\title{
Pobreza, desenvolvimento e comportamento humano: análise e conceituação sob o enfoque da economia comportamental
}

\author{
Poverty, development and the human behavior: analysis and conceptualization of poverty \\ under the focus of behavioral economics
Ohanna Larissa Fraga Pereira ${ }^{\mathrm{I}}$, Caroline Lucion Puchale" ${ }^{\mathrm{II}}$, Thiago Matheus de Paula Sousa ${ }^{\mathrm{III}}$, Nayara Felix Teixeira ${ }^{\mathrm{IV}}$ e Sibele Vasconcelos de Oliveira ${ }^{\mathrm{V}}$

\begin{abstract}
RESUMO
Inspirado nas recentes pesquisas do comportamento econômico humano e nas conceituações de pobreza e desenvolvimento humano, este estudo objetiva analisar como a economia comportamental se insere no complexo estudo desses fenômenos. Através de pesquisas bibliográficas, busca-se fornecer uma interpretação da trajetória do pensamento científico da pobreza e do desenvolvimento humano, desde suas primeiras conceituações e formas de mensurações, sob perspectivas unidimensionais, medidas principalmente através dos níveis de renda; até a visão contemporânea econômica comportamental, sob a perspectiva multidimensional agregadora de múltiplos fatores sociais, econômicos e subjetivos. À luz da abordagem econômica comportamental, emergem estudos que se preocupam em interpretar esses fenômenos por meio da análise dos obstáculos internos à mente dos indivíduos, defendendo a aplicação de pequenas intervenções, os nudges, na tomada de decisão dos agentes, buscando o aumento do bem-estar geral através de escolhas acertadas de políticas de combate à pobreza e de expansão do desenvolvimento humano.
\end{abstract}

Palavras-chave: Economia Comportamental da Pobreza; Evolução do Pensamento Científico da Pobreza; Desenvolvimento Humano.

\begin{abstract}
Inspired by recent research on human economic behavior and the concepts of poverty and human development, this study aims to analyze how behavioral economics is embedded in the complex study of these phenomena. Through bibliographical research, it is sought to provide an interpretation of the trajectory of scientific thinking about poverty and human development, from its first conceptualizations and forms of measurement, under onedimensional perspectives, measured mainly through income levels; to contemporary behavioral economic view, from the multidimensional perspective aggregating multiple social, economic and subjective factors. In the light of the behavioral economic approach, studies emerge that are concerned with interpreting these phenomena by analyzing the internal obstacles to the individuals' minds, defending the application of small interventions, the nudges, in the decision making of the agents, seeking the increase of the good - general consensus through sound policy choices to combat poverty and expand human development.
\end{abstract}

Keywords: Behavioral Economics of Poverty; Evolution of the Scientific Thought of Poverty; Human development.

\footnotetext{
I Mestranda do Programa de Pós-Graduação em Economia e Desenvolvimento da Universidade Federal de Santa Maria.RS, Brasil. E-mail: ohanna_larissa1@hotmail.çom

IIMestranda do Programa de Pós-Graduação em Economia e Desenvolvimento da Universidade Federal de Santa Maria.RS, Brasil. E-mail: carolpuchale@gmail.com

IIIGraduando em Ciências Econômicas na Universidade Federal do Ceará, CE, Brasil. E-mail: thiagomatheus.rns@gmail.com

Iv Graduanda em Ciências Econômicas na Universidade Federal do Ceará, CE, Brasil. E-mail:nayaraft1104@gmail.com

vProfessora Adjunta do Programa de Pós-Graduação em Economia e Desenvolvimento e do Departamento de Economia e

Relações Internacionais da Universidade Federal de Santa Maria. RS, Brasil. E-mail: sibele_oliveira@yahoo.com.br
} 


\section{Introdução}

As discussões sobre progresso social apresentaram profundas modificações desde a introdução do primeiro Relatório de Desenvolvimento Humano (RDH) nos anos de 1990. A partir de então, expandiram-se os estudos que se propunham a discutir o fenômeno do desenvolvimento sob a ótica de inúmeros indicadores sociais e monetários, contrariando a visão tradicional de progresso econômico (que só considerava nas análises o PIB per capita).

Destarte, o desenvolvimento é entendido como uma evolução conjunta do bem-estar social dos indivíduos, de forma que quanto melhores forem as condições monetárias, educacionais, de saúde, moradia, saneamento básico, dentre outros fatores, maior será o desenvolvimento econômico e social de determinada sociedade. Assim, um dos fatores que deve ser combatido na busca de um maior desenvolvimento econômico e social é a pobreza, este fenômeno já está incluso nos Objetivos do Milênio, propostos pelos Estados-membros da Organização das Nações Unidas (ONU). Dentro da esfera de propostas, a ONU espera a erradicação da pobreza em todas as suas multidimensões, bem como em todas as nações do mundo.

Para melhor entender o conceito de pobreza, é preciso, sobretudo, observar a sua evolução ao longo do tempo. Towsend (2006) destaca três perspectivas formuladas a partir de 1880: a pobreza de subsistência, a de necessidades básicas e a pobreza como privação relativa. Apenas por volta do século XXI, Sen (2013) desenvolveu o conceito de pobreza como privação de capacidades, o qual vigora até os dias atuais. Em síntese, a pobreza de subsistência relaciona-se às questões de sobrevivência física, ou seja, à falta de nutrição necessária para manter as condições vitais. Já o conceito das necessidades básicas refere-se à privação de consumo, relacionado a necessidades de alimentação, vestuário, residência, e de serviços essenciais como saneamento básico, acesso a instituições de saúde e de educação e entre outros. A pobreza como privação relativa diz respeito à situação em que o indivíduo não detém de recursos e condições de vida adequada para incluir-se no meio social no qual convive, seja para relacionar-se ou para seguir o padrão de vida do restante da comunidade. Por fim, a pobreza como privação de capacitações, relacionada à privação de multifatores, exibe um conjunto mais amplo e completo, pois além de incluir critérios econômicos, sociais e demográficos, também abrange questões políticas e culturais, sendo, por conseguinte, mais realista no que diz respeito à observação do bem-estar social (SEN, 2003).

Portanto, nota-se que o estudo evolui de medidas unidimensionais, focadas na definição de linhas de pobreza monetárias, para medidas multidimensionais que incluem outras dimensões da vida, como saúde, educação, saneamento e etc., também relevantes para a conceptualização de pobreza. Nesse sentido, o campo de pesquisa que vem ganhando destaque nas discussões e mensurações da pobreza multidimensional e do desenvolvimento é a economia comportamental. Tal área busca lançar luz sobre o estudo desses fenômenos valendo-se de insights comportamentais que agregam melhores explicações sobre a pobreza e o desenvolvimento através do comportamento dos agentes.

Os economistas comportamentais, ao estudar a pobreza e a suas consequências na economia, têm verificado que a circunstância de vida das pessoas pobres pode ocasionar obstáculos psicológicos e, assim, influenciar suas tomadas de decisões, dificultando a saída da pobreza ou até mesmo reforçando-a. Neste caso, tal literatura acredita que indivíduos pobres agem de maneira antagônica à intenção de superar a condição de privação, ou seja, existem diversos desafios em suas tomadas de decisão que fazem com que os agentes não consigam ter lucidez em suas escolhas, o que os mantém na condição de pobres e retardam a busca pelo desenvolvimento humano das nações.

Assim sendo, o presente estudo propõe-se a responder como a abordagem da economia comportamental se insere no complexo estudo da pobreza e do desenvolvimento humano. Tem-se por objetivo principal fornecer uma interpretação da trajetória do pensamento científico da pobreza e do desenvolvimento humano, desde suas primeiras conceituações e formas de mensurações, até a visão econômica comportamental que surgiu nas últimas décadas.

Dessa forma, a redação estrutura-se da seguinte maneira: a primeira seção traz a introdução acerca do que será tratado. A segunda seção abrange o referencial teórico, que se divide em subseções que tratam da trajetória da conceituação da pobreza, trazendo uma interpretação desse fenômeno desde os primórdios do capitalismo até as abordagens da pobreza de subsistência e de necessidades básicas; conceitua a abordagem das capacitações de Amartya Sen e sua visão multidimensional; aborda o pensamento dos teóricos economistas comportamentais sobre pobreza e desenvolvimento humano através de uma visão desses conceitos como obstáculos internos à mente dos indivíduos; e traz implicações sobre a abordagem da economia comportamental, abordando como essa visão se insere no campo do desenvolvimento e da pobreza. A terceira seção traz as considerações finais sobre o tema.

\section{A trajetória da conceituação da pobreza}

O conceito de pobreza passou por uma evolução no decorrer do tempo e ainda hoje inspira pesquisadores do campo econômico. Os primeiros enfoques sobre tal fenômeno remontam os primórdios do capitalismo, quando a pobreza começou a ser discutida por dirigentes de pequenas comunidades que buscavam compreender as causas desse fenômeno e procuravam formular estratégias para sanar as condições de penúria vivida por uma parcela da população (CODES, 2008). Com o avanço da industrialização, as condições de miséria da classe trabalhadora tornaram as pequenas políticas sociais, que ocorriam em instituições isoladas, insuficientes, de forma que os debates sobre pobreza alcançassem proporções macroeconômicas. A pobreza 
que antes era vista por um enfoque unidimensional, medida apenas pelos níveis de renda, passou a buscar uma abordagem em que multifatores sociais e econômicos fossem agregados em sua mensuração (MESTRUM, 2002).

Como confirmado por Romão (1982, p. 356): "não existe consenso entre os estudiosos da pobreza quanto à linha "ótima" da pobreza num sentido preciso, ou a uma medida relativa "ótima" no sentido de que melhor refletisse a posição relativa dos pobres". Assim, Townsend (1979), Romão (1982), Crespo e Gurovitz (2002), Codes (2008) e Martini (2009), estabelecem a existência de três noções iniciais da abordagem da pobreza, a saber: absoluta, relativa e subjetiva (FIGURA 1). Após estabelecido estas três noções, surgem os conceitos teóricos da pobreza indicadas na Figura 1.

Figura 1 - Noções e conceitos de pobreza

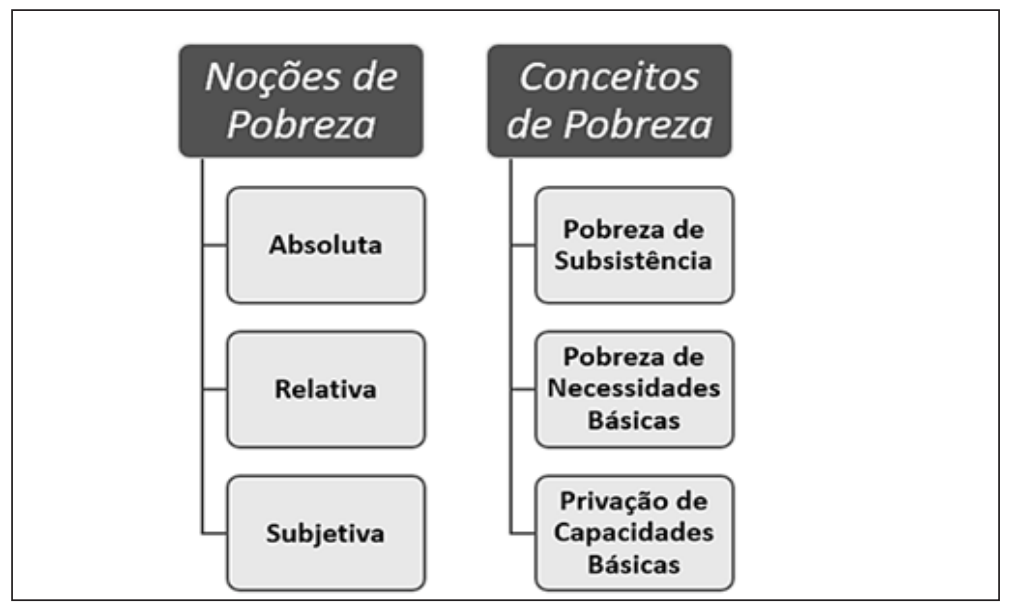

Fonte: Elaboração Própria

Dentre as noções de pobreza, a forma mais difundida encontra-se na conceituação absoluta, encarada como a pobreza material, onde um indivíduo é considerado pobre quando não possui as condições mínimas para sobreviver, ou seja, não possui condições de manter sua existência física (CRESPO; GUROVITZ, 2002). A segunda noção de pobreza é a relativa, segundo Townsend (1979), é aquela advinda da desigualdade na distribuição de renda, isto é, pobre é o indivíduo que não possui as mesmas oportunidades e condições econômicas e sociais do restante da sociedade em que está inserido. A última noção, é a pobreza subjetiva que advém do sentimento do indivíduo de sentir-se pobre, é a sensação de exclusão social. Como confirmado por Martini (2009, p. 10), nesta abordagem "ser pobre é entendido como ter um sentimento individual de possuir menos que o necessário para cumprir os compromissos sociais vigentes, em termos familiares, culturais e de posição social e profissional que cada indivíduo apresenta”.

A partir destas três noções de pobreza, afloraram diversos conceitos teóricas, como demonstrado na Figura 1. A abordagem de subsistência nasceu dos trabalhos de nutricionistas ingleses e predominou até a década de 1950. Essa concepção afirma que um indivíduo é considerado pobre quando não possui recursos monetários suficientes para manter um mínimo de alimentos necessários para sua sobrevivência física (TOWNSEND, 1979; TOWNSEND, 1987; CODES, 2008; MARTINI, 2009). O principal problema apontado por Townsend (1987) ao utilizar-se da concepção de subsistência, é que as necessidades humanas são vistas como necessidades físicas e não como necessidades sociais porém, os indivíduos são seres sociais e não físicos.

A concepção da pobreza de necessidades básicas surge formalmente, segundo Townsend (1987), na International labour Office's World Employment Conference em Genebra no ano de 1976 e objetiva ampliar os itens de consumo das famílias. Nesse caso, o indivíduo é considerado pobre se, além de não possuir renda suficiente para manter-se bem nutrido, vestido e com moradia adequada, também não possui acesso a um grande número de serviços básicos de ordem social e econômica, como acesso a água potável, saneamento básico, transporte público, saúde, educação, serviços culturais, entre outros (TOWNSEND, 1979; TOWNSEND, 1987; CODES, 2008; MARTINI, 2009). Nesta perspectiva, Townsend (1979), argumenta que o conceito de pobreza deve concentrar-se tanto nas necessidades físicas como sociais. Portanto, a pobreza vista sob as necessidades básicas ultrapassa a ideia de sobrevivência física e agrega uma gama diversificada de dimensões.

A literatura acerca da pobreza foi demonstrando aos poucos que esse fenômeno não está desassociado da cidadania, pois, ser pobre "explicita justamente iniquidade inscrita na trama social" (CODES, 2008, p. 16). O avanço da investigação científica sobre o tema recai sobre a compreensão desse fenômeno como uma questão que ultrapassa o âmbito puramente econômico para ser visto como um problema de esfera social e a sua relatividade decorre, sobretudo, da preocupação das desigualdades sociais. Dessa forma, a abordagem da pobreza como privação de capacidades básicas desenvolvida por Amartya Sen, abre um amplo debate para a conceituação desse fenômeno. O autor insere a reflexão acerca da pobreza no campo legal, político e social. Além disso, seu trabalho avança no sentido de entender a pobreza como um fenômeno agregador de multifatores, criando uma nova concepção que repousa na premissa de pobreza como uma privação de capacidades dos indivíduos. 


\section{Pobreza como privação de capacidades básicas dos indivíduos}

A concepção de pobreza como privação de capacitações nasce na ideia de Amartya Sen. Sua abordagem expande o campo das necessidades fundamentais, incorporando diversos aspectos que não pertenciam às demais formulações vistas anteriormente. Para Crespo e Gurovitz (2002), a conceituação de Sen incorpora variáveis mais amplas que captam privações sofridas em distintas esferas da vida. Portanto, ser pobre na visão de Sen (2013) perpassa a privação material ou da escassez de renda, é sobretudo a privação das capacidades básicas.

Sen (2013) entende capacidade como uma liberdade substantiva de realizar combinações alternativas de funcionamentos, ele afirma que "isso envolve uma certa concepção da vida como uma combinação de várias atividades e modos de ser. A capacidade reflete a liberdade pessoal de escolher entre vários modos de viver" (SEN, 1993, p.317). O próprio autor exemplifica tal conceito comparando um indivíduo abastado que jejua por vontade própria e um indivíduo pobre que passa fome forçadamente. Em sua concepção, o primeiro indivíduo pode escolher comer bem e ser bem nutrido, diferentemente do segundo, portanto, isso confere ao primeiro agente um "conjunto capacitário" inexistente ao segundo (SEN, 2013).

Nesse sentido, Codes (2008) afirma que a abordagem das capacitações engloba também as definições de pobreza absoluta e relativa, uma vez que ter privações de renda e mercadorias podem levar a privações também capacitarias. A autora reconhece que a disponibilidade de vários bens e recursos à disposição de um indivíduo não o torna capacitado para obtê-los, pois esse conjunto de bens e recursos está em função de muitos fatores tanto legais como econômicos. Portanto, nessa perspectiva de privação de capacidades básicas, um indivíduo não passa fome e situações de miséria por não ter alimentos e outros bens disponíveis, mas porque ele não tem capacidade de obtê-los.

Sen (2013) reconhece o papel da pobreza monetária em sua teoria, e afirma que não se pode desprezar o fato de que um nível de renda baixo pode ser um dos principais determinantes da pobreza, pois afeta as capacidades do indivíduo. Em sua análise, destaca o nível de renda como um dos determinantes bastante considerado principalmente em países em desenvolvimento. Entretanto, deixa claro que a perspectiva monetária deve ser encarada somente como um instrumento que fortalece a pobreza e não como o verdadeiro motivo que coloca os indivíduos neste estado. $\mathrm{O}$ autor ressalta, por exemplo, que ter rendas iguais não significa igualdade do potencial humano de fazer o que valoriza, indivíduos incapacitados fisicamente não podem realizar os mesmos funcionamentos que uma pessoa com o corpo hábil mesmo que tenham ambos a mesma renda (SEN, 2001). Muito mais do que um agente não possuir renda, pior é não ter oportunidades (de moradia, vestuário, saneamento básico, trabalho, saúde, entre outros) para que possa inteirar sua realidade com dignidade (SEN, 2013). Sen (1993), utiliza o argumento de Aristóteles para defender que a riqueza não é o que os homens buscam, é apenas um meio de obtenção de outros bens, portanto a renda seria um meio e não um fim. Dentro dessa visão, Crespo e Gurovitz (2002) reiteram essa concepção afirmando que:

O que a perspectiva da capacidade faz na análise da pobreza é melhorar o entendimento da natureza e das causas da pobreza e privação desviando a atenção principal dos meios (renda) para os fins que as pessoas têm razão para buscar e para as liberdades de poder alcançar esses fins. Ambas as perspectivas, a noção de pobreza como inadequação de capacidade e a noção de pobreza como baixo nível de renda, estão vinculadas, uma vez que a renda é um meio fundamental na obtenção de capacidade. E, quanto mais capacidades, maior o potencial produtivo de uma pessoa e, consequentemente, maior a chance de se obter uma renda mais elevada. Note que uma renda mais elevada não significa necessariamente capacidades maiores. Essa relação, portanto, é importante na eliminação da pobreza de renda (CRESPO \& GUROVITZ, 2002, p.6).

Além dessa noção de pobreza estritamente monetária, a abordagem das capacitações de Amartya Sen também se contrapõe à perspectiva utilitarista de valor utilizada frequentemente na teoria tradicional do bem-estar. Esta abordagem relaciona valor somente à utilidade individual, a qual pode ser determinada como uma condição mental definida por prazer, dor, felicidade, satisfação dos desejos e etc. Sen (1993, p.319) afirma que "essa perspectiva subjetiva tem sido extensivamente utilizada, mas pode ser enganosa, pois pode ser incapaz de refletir a real privação de uma pessoa". Para o autor, ao considerar-se a utilidade medida pelo estado mental do indivíduo, uma pessoa indigente que vive na miséria pode não estar mal caso verifique-se que tal agente admite a situação em que vive com resignação e silêncio. O autor alerta para o fato de que quando as pessoas passam por longos períodos de situações de privação, elas buscam capturar o prazer das pequenas coisas, reduzindo, muitas vezes, seus desejos a proporções mais modestas e realistas, deixando de persistir em queixas frequentes. Dessa forma, a privação desses indivíduos não pode ser capturada por escalas de condição mental, mesmo que eles vivam em condições inadequadas de alimentação, educação, saúde e entre outros fatores. Essa questão pode, inclusive, ter influência no campo das políticas públicas, uma vez que a acomodação dos entes públicos diante de profundas privações e vulnerabilidades sociais, pode surgir baseada na ausência de demandas públicas e reivindicações populares por melhores condições de vida (SEN, 1993).

Salama e Destremau (2001) afirmam que na teoria de Sen a noção de bem-estar ocupa um lugar central, o autor entende que bem-estar é uma questão de estar bem, ou seja, de possuir atributos como ser educado, saudável e bem nutrido. Desse modo, ao procurar mensurar o padrão de vida, deve-se estar atento para a própria vida e não para a posse de mercadorias. Enquanto uma combinação orçamentária representa, no universo das mercadorias, a liberdade para comprar uma cesta de bens, a combinação de capacidades representa, no universo dos funcionamentos, a liberdade de escolher a vida que se quer viver. 
Nota-se que a percepção de pobreza elaborada por Amartya Sen trouxe uma profunda evolução para a área. A abordagem das capacitações libertou-se de uma visão unidimensional focada somente na renda ou na utilidade individual e passou a agregar multi fatores, constituindo a conceituação da pobreza multidimensional. Desta maneira, a pobreza multifacetada é entendida como o estado de privação que um indivíduo possui quando não dispõe de acesso a serviços básicos, por não ter seus direitos sociais garantidos ou até ser desprovido de levar uma vida que almeja. Na visão de Wilber (1975), o entendimento da pobreza como falta de renda tornou-se parcial e passou a caracterizar-se como um fenômeno agregador de multifatores com natureza extremamente complexa. A pobreza atualmente ganhou ampla aceitação como algo que não se refere apenas à obtenção de mercadorias, mas também à falta de oportunidades de exercer a vida que se deseja socialmente. As múltiplas carências vividas pelos indivíduos pobres, dão a eles uma existência curta com muitas complicações e perigos, provocando nessas pessoas sentimentos ruins de impotência, desesperança vulnerabilidade, incapacidade política e entre outros.

Dessa forma, por mostrar-se mais apropriada à realidade, a perspectiva multidimensional da abordagem das capacitações de Sen tem alcançado distintas áreas do saber. Sua ligação com o desenvolvimento humano demonstra o quanto tornou-se importante para os países buscarem a erradicação da pobreza como um dos pontos principais na busca de maiores índices de desenvolvimento humano. Mas, a pobreza que se busca extinguir, na área do desenvolvimento, é também vista pela ótica multidimensional da conceituação das capacitações nascida no pensamento de Amartya Sen. Nesse sentido, o entendimento do desenvolvimento humano também passou a ser multidimensional.

\section{Pobreza e desenvolvimento humano}

O estudo do desenvolvimento humano passou a ter maior enfoque a partir de 1990, quando foi lançado o primeiro Relatório de Desenvolvimento Humano (RDH) elaborado pelo Programa das Nações Unidas para o Desenvolvimento (PNUD). De acordo com o PNUD (2010), as pessoas passaram a ser vistas como a verdadeira riqueza das nações e, por isso, o objetivo primordial do desenvolvimento tornou-se promover ambientes com maiores possibilidades de escolhas aos indivíduos, onde eles possam desfrutar de uma vida saudável, longa e com acesso ao conhecimento, ou seja, que possam viver com dignidade. Dessa forma, Sen (2013) ressalta que o estudo do desenvolvimento humano passou a sugerir uma análise das condições de vida dos indivíduos em cada sociedade e as liberdades substantivas logradas por eles. O PNUD (2010) destaca que o RDH de 1990 já trazia temas relacionados às privações dos indivíduos, à desigualdade entre os países e à capacitação dos agentes.

Nesse sentido, entende-se que o desenvolvimento deve, portanto, fornecer oportunidades a cada indivíduo através da formação de capacidades humanas por meio do acesso à saúde e educação de qualidade, condições adequadas de moradia e outros fatores que permitam melhoras no padrão de vida das pessoas. Portanto, esse novo conceito diferencia-se da concepção de desenvolvimento utilizada até então, onde o progresso de um país era medido exclusivamente pelo Produto Interno Bruto per capita (PIB per capita) e aproxima-se do conceito de pobreza proposto na abordagem das capacitações de Amartya Sen (SEN, 2013, VAZ; SILVA, 2013). Desse modo, observa-se que os autores relacionam cada vez mais o desenvolvimento humano com a pobreza.

Junto à teoria, surge a necessidade de mensurar de forma prática o desenvolvimento humano por meio de algo tão objetivo quanto o PIB. Surge, então, no RDH de 1990, o Índice de Desenvolvimento Humano (IDH), pautado, na versão atual, em três dimensões principais e quatro indicadores, como mostra a Figura 3.

\section{Figura 3 - Dimensões e Indicadores do IDH}

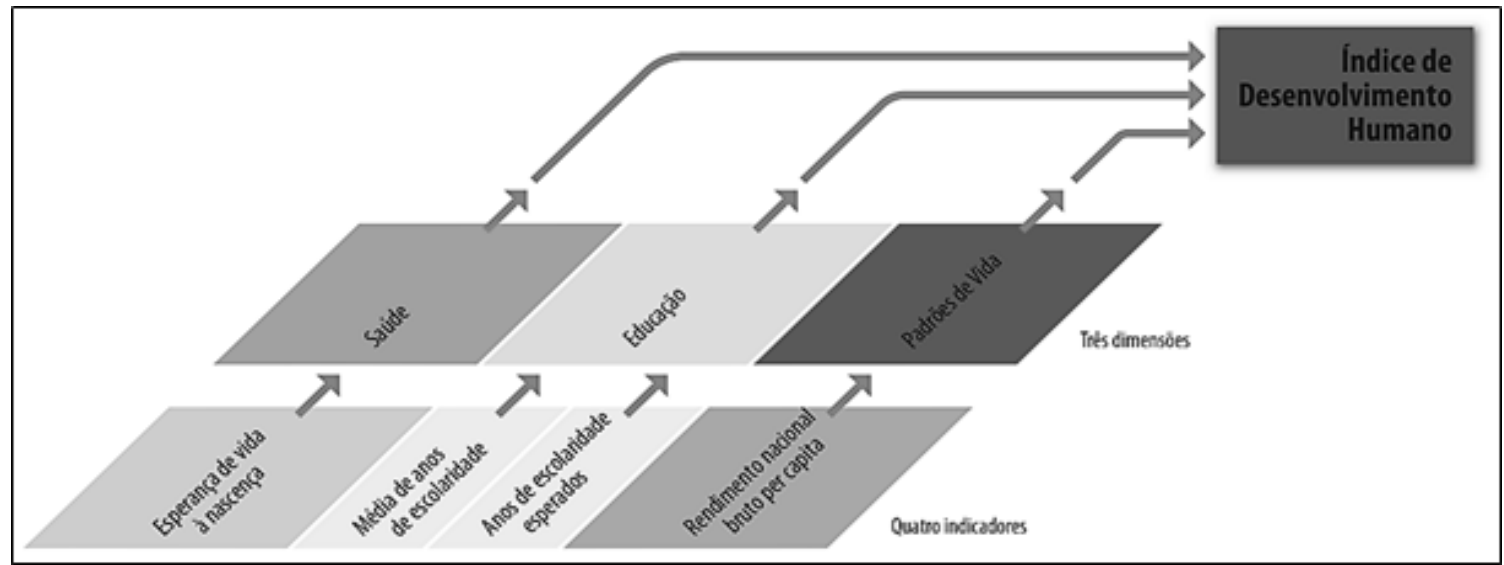

Fonte: Elaboração própria com base em PNUD (2010) 
Segundo Guimarães e Jannuzzi (2005), o caráter multivariado do IDH faz tratar o desenvolvimento humano de maneira mais completa que os chamados Indicadores de Primeira Geração como o PIB per capita. Além disso, ele é considerado um indicador compreensível, com metodologia simples e de fácil aplicação a diferentes realidades. Porém, não escapa às limitações, dentre as quais, Cardoso (1998) destaca que este índice estabelece padrões mínimos universais de qualidade de vida que devem valer para todos os países sem respeitar a cultura, particularidades regionais, hábitos de consumo e até mesmo o grau de satisfação da população de dado local. Não se pode negar, todavia, que os avanços trazidos pelo IDH levam a um entendimento social mais amplo que a abordagem do crescimento econômico apenas centrado no PIB. Destaca-se ainda que pela a visão de alguns autores, o IDH é um dos indicadores que tenta medir a pobreza de forma mais eficiente (ROMERO, 2006).

Sen (1993) destaca a confusão feita pelos dirigentes na elaboração de políticas públicas que têm a busca pelo aumento dos níveis de renda e crescimento econômico como critérios principais na promoção do desenvolvimento. O autor ressalta que buscar prosperidade econômica não é um erro, porém esse objetivo não pode ser o principal, tampouco se sobrepor a aspectos da vida humana. Um exemplo de país que demonstra essa concepção é a África do Sul, uma nação, a qual, à época, o ator destacava como uma sociedade rica em termos econômicos, porém com baixa qualidade de vida para os seus habitantes. Logo, a prosperidade econômica deveria ser vista apenas como um meio de enriquecer a vida dos indivíduos.

Ademais, a pobreza, entendida como um dos fatores de destaque no estudo do desenvolvimento humano e que se relaciona negativamente com altos níveis de IDH, também não pode ser vista, segundo o autor, apenas como privação de renda. Quando se trata de formular políticas públicas visando melhorar o desenvolvimento humano de uma sociedade, justificar investimentos públicos em educação, saúde, moradia e etc. como um meio de redução da pobreza, seria confundir os fins com os meios. Para o autor, a pobreza é entendida como uma privação da vida que o indivíduo de fato pode levar e as liberdades que ele possui. Logo, a expansão das capacidades humanas auxilia tanto direta como indiretamente a enriquecer a vida dos indivíduos e a tornar as privações cada vez mais raras e menos crônicas, possibilitando-os alcançar níveis cada vez maiores de desenvolvimento humano (SEN, 2013).

Portanto, o fenômeno do desenvolvimento humano parece agregar uma infinidade de fatores que pertencem a processos não só econômicos como de ordem social e subjetiva. Seu desafio principal é, sobretudo, aumentar as liberdades individuais e dar espaço para que as capacidades de realização se desenvolvam. Constantemente os indivíduos se aprisionam em limitações, as quais os impedem de exercer a vida que desejam em sociedade. Barreiras essas que se formam, muitas vezes, em razão das circunstâncias nas quais os agentes nascem inseridos. Logo, o desenvolvimento humano enfrenta questões complexas, assim como a pobreza que é um dos seus principais aspectos negativos (SEN, 1993).

De acordo com Sen (2001), apesar de existir uma grande quantidade de trabalhos que exploram o desenvolvimento numa perspectiva de avaliação da qualidade de vida e de necessidades básicas, chamando atenção para aspectos negligenciados do desenvolvimento econômico e social, esses estudos são ignorados pela economia mainstream. O foco na avaliação utilitarista possui prestígio intelectual nessa teoria e bloqueia ideias alternativas, mesmo que pareçam sensatas. Portanto, mesmo que o desenvolvimento humano, bem como a pobreza, em seus aspectos multidimensionais, tenham a boa vontade de alavancar pesquisas e construir novos paradigmas que ressaltem as verdadeiras privações sofridas pelos indivíduos ou mostrem, de fato, a realidade que necessita ser mudada para que os países finalmente consigam lograr o título de desenvolvidos, há toda uma teoria já estabelecida por trás capaz de barrar tais avanços.

Desse modo, apesar de caminhar lentamente, a trajetória das conceituações de pobreza e desenvolvimento humano, bem como suas formas de medição, avançam no decorrer do tempo. Recentemente, tais áreas ganharam a atenção de uma nova abordagem, que busca explicar, sobretudo a pobreza, por meio de obstáculos internos à mente dos indivíduos. A área da economia comportamental adentra esses complexos campos de estudo para trazer um novo olhar para essas duas questões e buscar contribuir para a criação de políticas mais eficazes que consigam, de fato, um avanço da erradicação da pobreza e na conquista de maiores níveis de desenvolvimento humano para as nações.

\section{Economia comportamental da pobreza e do desenvolvimento: uma análise a partir dos obstáculos internos à mente indivíduos}

Nas últimas décadas o estudo da economia comportamental vem ganhando impulso e conquistando espaço na academia através de suas aplicações empíricas. Sua abordagem metodológica mais eclética e experimental, permite a explicação de fenômenos a partir de comportamentos subjetivos dos indivíduos (MURUMATSU; ÁVILA 2017). Recentemente, Bertrand, Mullainathan e Shafir (2004), Datta e Mullunaithan (2014) e Banerjee e Duflo (2012) buscaram lançar luz no estudo da pobreza e do desenvolvimento humano a partir de insights dos estudos comportamentais, agregando a essas áreas resultados que melhor explicam esses dois fenômenos através do comportamento dos agentes.

A abordagem comportamental sugere, de antemão, que esse programa de pesquisa busca complementar a abordagem das capacitações de Sen (2013), que busca a liberdade e expansão das capacitações dos indivíduos. Portanto, o estudo do comportamento econômico dos agentes procura entender os desafios da pobreza e do desenvolvimento humano em termos de obstáculos internos aos indivíduos, os quais frequentemente incorrem em atalhos mentais, como as heurísticas, e em erros sistemáticos na tomada de decisão, os vieses cognitivos (MURAMATSU; AVILA, 2017). Dessa forma, o potencial do estudo dessa área 
permite entender quais as barreiras internas que determinam o comportamento de indivíduos pobres, bem como, possibilita criar melhores mecanismos de ajuda para combater a pobreza a partir de uma análise intrínseca dos agentes econômicos e alavancar o desenvolvimento humano das nações.

Em consonância com essa abordagem, o Banco Mundial (2015) demonstrou a importância do comportamento humano na compreensão do desenvolvimento econômico ao criar o relatório "Mente, Sociedade e Comportamento", onde observa que o entendimento das influências psicológicas e sociais sobre a tomada de decisão possuem impacto relevante na pobreza e no desenvolvimento. Com efeito, o aporte da economia comportamental, enfatizando a escassez como fator que influencia a capacidade de cognitiva dos indivíduos, ajuda compreender o complexo comportamento decisório de agentes em circunstâncias não só de vulnerabilidade financeira, como também na condição de privações de oportunidades e de direitos, já que a pobreza, interpretada pela economia comportamental, é conceituada como multidimensional, corroborando com a ideia de Amartya Sen (MULLUNATHAN; SHAFIR, 2016). Logo, a pobreza possui múltiplas facetas, que vão desde escassez de renda, até dimensões institucionais, sociais, motivacionais e cognitivas (ANAND; LEA, 2011).

Nesse contexto, a economia comportamental da pobreza concentra-se em estudos os quais sugerem que as pessoas pobres enfrentam diferentes desafios internos de tomada de decisão que, em situações imprevisíveis, acabam impedindo esses indivíduos de escolher melhores opções para si, o que poderia não ocorrer se tais limitações intrínsecas não existissem. Essa visão de economia, distancia da abordagem mainstream, que acredita que a exclusão e a falta de capacitação dos indivíduos, que os torna privados, decorrem somente de processos externos aos agentes, referentes à estruturação social, à trajetória histórica da sociedade e entre outros fatores (BERTRAND; MULLAINATHAN; SHAFIR, 2004). Dessa forma, a recente literatura aborda alguns desses obstáculos intrínsecos aos indivíduos que prejudicam a tomada de decisão dos agentes que encontram-se em situação de pobreza. São esses: escassez de autocontrole; escassez de atenção; e escassez de capacidade cognitiva. Ressalta-se que essas três dificuldades não são mutuamente exclusivas, de maneira que podem afetar simultaneamente a tomada de decisão dos pobres (SPEARS, 2011).

A escassez de autocontrole pode ser definida como a falta de força de vontade, ou a incapacidade de executar planos previamente estabelecidos. Essa é uma tarefa de difícil esforço, assim como a de regular os próprios pensamentos e emoções (KAHNEMAN, 2016). De acordo com Delaney e Lades (2015), a falha do autocontrole tende a ocorrer quando a tentação domina a capacidade do indivíduo de resistir. Para Datta e Mullunaithan (2014) o autocontrole é um recurso escasso e, portanto, apresenta estoque limitado, de modo que o seu uso em uma tarefa diminui o seu valor disponível para outras atividades. Dessa forma, acredita-se que a pobreza esgota o autocontrole de maneira mais rápida, pois os pobres estão frequentemente sujeitos a mais tentações (BANERJEE; DUFLO, 2012).

A pobreza gera, por sua vez, um foco intenso em escolhas a serem realizadas no presente em detrimento do futuro, de modo que as consequências das escolhas temporais inconsistentes são mais severas para os pobres (MURAMATSU; ÁVILA, 2017). Banerjee e Mullainathan (2010) observam que os indivíduos alocam seus gastos em bens de tentação e naqueles que não são de tentação, demostrando que o desejo é decrescente, isto é, a fração marginal do dólar gasto em bens de tentação diminui com o consumo em geral. De acordo com os autores isso gera uma situação de armadilha da pobreza, pois leva os indivíduos pobres a escolherem gratificações imediatas, de modo que não buscam realizar investimentos de alto retorno que ocorreriam em pontos mais distantes do tempo. Isso, no entanto, não pode ser entendido como um exemplo de irracionalidade, pois, embora as privações limitem as escolhas individuais, existem vários fatores situacionais - como trabalho, ambiente incerto e ineficácia de instituições - que remuneram altamente recompensas imediatas (BANERJEE; DUFLO, 2007). Entretanto, é fato que um indivíduo em condições de pobreza tende a preferir o consumo imediato em detrimento de melhores opções futuras (MURAMATSU, 2015).

O segundo obstáculo interno, a escassez de atenção, revela que a atenção dos indivíduos pode ser limitada devido a situações de privações. Para os autores Shah, Mullainathan e Shafir (2012), a pobreza ocuparia excessivamente a atenção dos indivíduos, reduzindo o desempenho em decisões importantes e causando excesso de ansiedade, principalmente em decisões financeiras. Desse modo, a pobreza "absorve a atenção, desencadeia pensamentos intrusivos e reduz recursos cognitivos" (MANI et al, 2013, p. 980).

Uma consequência dessa teoria pode ser então vista na tomada de empréstimos de curto prazo a juros altos por indivíduos de baixa renda. Os mesmos autores observaram que indivíduos pobres consomem frequentemente recursos que demandam grande atenção para a realização de necessidades básicas, de modo que sobra menos recursos para outros problemas. Portanto, a escassez cria um foco de atenção sobre as despesas urgentes, cuja concentração seria direcionada aos benefícios de um empréstimo, mas não seria levado em conta o seu real custo. Logo, a escassez de atenção leva a uma maior tendência de tomada de empréstimos mesmo que não sejam uma boa alternativa (SHAH; MULLAINATHAN; SHAFIR, 2012).

O obstáculo relacionado à escassez de capacidade cognitiva apresenta um papel muito importante na tomada de decisão, pois a cognição é um recurso entendido como o processo que direciona a atenção e inibe comportamentos automáticos na tomada de decisões. A abordagem da economia comportamental, apoia-se na ideia de racionalidade limitada proposta por Simon (1955), a qual aponta fragilidades no uso da lógica para chegar a padrões de comportamento maximizadores dos indivíduos na resolução de problemas de alta complexidade. A literatura recente sobre o comportamento econômico, corrobora com o exposto por Simon (1955), mostrando que os recursos cognitivos dos indivíduos demonstram-se sempre limitados (DATTA; 
MULLAINATHAN, 2014). Ao lidar com pessoas que vivem em situação de vulnerabilidade econômica, a situação pode ser ainda mais agravante, pois esses indivíduos precisam empregar mais energia mental em atividades que buscam assegurar ao menos as necessidades básicas como alimentação, saúde, moradia e entre outros, quando comparado a indivíduos que possuem um amplo acesso a serviços de qualidade com condições melhores de saúde, infraestrutura, educação e etc. (BANCO MUNDIAL, 2015).

Condições de privações econômicas, desse modo, podem absorver recursos mentais e cobrar um ônus cognitivo, de maneira que interfere no julgamento e na tomada de decisão dos agentes (MULLINATHAN; SHAFIR, 2016). Mani et. al (2013) verificam esse estado a partir de um estudo realizado com agricultores que cultivam cana de açúcar na Índia. Nesse trabalho, foram aplicados testes imediatamente antes e depois da colheita - momento de arrecadação de receita para esses indivíduos - e os resultados encontrados demonstraram grandes diferenças na tomada de decisão dos agentes. Descobriu-se que antes da safra os agricultores apresentaram pior desempenho nos testes cognitivos e estavam mais suscetíveis tomarem empréstimos e penhorarem seus pertences (MANI et al., 2013). Privar o desenvolvimento cognitivo dos indivíduos os fazem incorrer frequentemente em heurísticas, atalhos mentais, e pode levar os agentes a cometerem erros sistemáticos, chamados de vieses, que, frequentemente, não são as melhores opções disponíveis (KAHNEMAN, 2016).

\section{Implicações da economia comportamental no desenho de políticas e programas de desenvolvimento}

O potencial da utilização da economia comportamental para promoção de políticas de desenvolvimento tem originado uma literatura crescente na última década. A utilização de insights psicológicos, novas metodologias e novas conceituações teóricas trazem um maior realismo ao diagnóstico de questões complexas da pobreza, do desenvolvimento humano e à formulação de políticas destinadas à melhoria nos padrões de vida das sociedades. Portanto, essa abordagem ligada à observação do comportamento humano permite a compreensão de algumas das falhas dos programas de desenvolvimento e de políticas públicas destinadas à erradicação da pobreza (JÄNTTI; KANBUR, 2014; SARAIVA, 2013).

Muramatsu e Ávila (2017) afirmam que existem dois fatores substanciais que explicam porque a interdisciplinaridade entre a economia comportamental e a economia do desenvolvimento traz ganhos positivos para a sociedade em geral. O primeiro é o fator psicológico fraco dos programas, os quais são desenhados segundo a teoria tradicional da economia que entende os agentes como seres racionais que decidem sempre de modo a maximizar a sua utilidade esperada, não considerando a limitação de recursos cognitivos escassos (SARAIVA, 2013); e outro aspecto é o reconhecimento de experiências de campo, cujos ensaios clínicos randomizados tem apresentado relativo impacto na avaliação de programas, demonstrando grande influência de fatores psicológicos nas tomadas de decisão dos indivíduos (BANERJEE; DUFLO, 2012).

Embora um dos principais problemas dessa nova abordagem consista de questionamentos sobre o uso da metodologia experimental - como validade externa -, o estudo da tomada de decisão dos indivíduos em determinados contextos pode apresentar repercussões consideráveis na formulação de políticas públicas (BANCO MUNDIAL, 2015). Conforme Datta e Mullanaithan (2014), a economia comportamental pode ajudar a desenhar melhores programas de três formas: inicialmente, ela modifica a forma de como diagnosticar problemas, buscando sempre considerar outras possibilidades. Segundo, muda a forma de criar soluções, sugerindo que intervenções têm que se adaptar ao contexto inserido. Por fim, modifica a forma como é definido o escopo do problema, suscitando o debate de que a simples implementação do programa pode não solucionar os problemas.

Nesse sentido, vários estudos experimentais têm sido realizados e trazido resultados que apontam para as discussões realizadas pela economia comportamental para o campo da pobreza e do desenvolvimento humano. No campo da educação, Mullanaithan (2007) mostra em sua pesquisa com pais indianos, que manter os filhos na escola faz parte de uma tomada de decisão que ultrapassa a análise puramente racional dos custos e benefícios. O autor encontrou resultados que mostram que os pais gostariam de manter seus filhos na escola, porém não conseguem se comprometer com o plano. Vermeersch e Kremer (2004) observaram que o simples fato de o colégio fornecer merenda escolar faz com que os pais vejam isso como consequência positiva para que o filho permaneça na escola no curto prazo e sejam alfabetizados. Na área das microfinanças, Banerjee e Duflo (2012) chegaram à conclusão de que o maior acesso ao microcrédito e a serviços bancários não são suficientes para a inclusão das pessoas que vivem em situação de privações. Em seus estudos, os autores chegaram à conclusão de que os pobres entendem a importância da poupança como alternativa de enfrentamento de desafios futuros no meio em que estão inseridos, de alto risco e insegurança. Entretanto, os pobres parecem não ter facilidades no acesso a mecanismos de aproximação com a poupança formal. Ou seja, as políticas implementadas em prol do desenvolvimento e combate à pobreza com base na expansão das microfinanças, parecem não estar atingindo os seus verdadeiros alvos por questões que ultrapassam a pura racionalidade dos indivíduos.

Pautados nas consequências negativas devido a falhas de julgamento e tomada de decisões equivocadas, os economistas comportamentais passaram a defender os nudges, que são pequenas intervenções que alteram a arquitetura de escolha dos indivíduos de modo a neutralizar seus vieses cognitivos (MURAMATSU, 2015). Muitos estudiosos defendem que os nudges são inevitáveis para que se tenha uma expansão do desenvolvimento humano, e que tais medidas não alteram o padrão de escolha dos indivíduos, os quais possuem completa liberdade de mudar de direção (THALER; SUSTEIN, 2009). Entretanto, 
outros autores sugerem que essa é uma medida que ameaça os valores éticos de liberdade de escolha e autonomia dos sujeitos. Além disso, acreditam que essas interferências na escolha dos indivíduos possam reduzir seus potenciais de aprendizado. Mas o que a literatura tem mostrado é que os nudges têm contribuído para decisões que melhoram o bem-estar dos indivíduos (MURAMATSU, 2015).

Dentro dessa perspectiva, observa-se que a economia comportamental pode contribuir profundamente para a área da pobreza e do desenvolvimento humano, buscando tão somente alargar as perspectivas de debate sobre os ganhos de uma abordagem mais realistas das limitações da racionalidade. O desenho de políticas pode ser beneficiado ao levar em consideração, por exemplo, alguns dos recursos limitados apresentados acima, de maneira que pode auxiliar a criar melhores mecanismos de ajuda aos indivíduos que se encontram em situações de vulnerabilidade.

\section{Considerações finais}

Este artigo objetivou fornecer uma interpretação da trajetória do pensamento científico da pobreza e do desenvolvimento humano desde suas primeiras conceituações e formas de mensurações dos primórdios do capitalismo, até a visão econômica comportamental que surgiu nas últimas décadas. Diante do exposto, compreende-se que os conceitos de pobreza e desenvolvimento humano passaram por uma evolução gradual no decorrer do tempo. Ambos partiram de visões unidimensionais e chegaram a visões multidimensionais agregadora de multifatores explicativos desses fenômenos.

A pobreza, inicialmente, possuía a renda como único fator quantificável e o desenvolvimento era medido apenas pelo PIB per capita. Ambos evoluíram em termos conceituais, a primeira ganhou novas formas de medição e inúmeras conceituações no decorrer do tempo, até chegar a abordagem mais utilizada atualmente, que repousa na conceituação de Amartya Sen, que considera pobreza como privações das capacidades básicas. O conceito de desenvolvimento humano, que está intimamente ligado ao fenômeno da pobreza, também passou a ser visto pela ótica multifacetada e criou uma forma de medição em que agrega diferentes dimensões, o IDH, que também teve a contribuição de Sen em sua formulação. Dada a evolução de ambos os conceitos, a pobreza e o desenvolvimento começaram a ganhar espaço em uma nova agenda de pesquisa. O campo da economia comportamental passou a estudar tais conceitos pela ótica do comportamento dos indivíduos, levando em consideração os obstáculos psicológicos internos aos agentes econômicos.

$\mathrm{O}$ avanço do pensamento da pobreza gerou esforços para que, atualmente, a maior parte dos estudiosos sobre tal fenômeno já o enxerguem como algo complexo e multifacetado. Na análise de Sen (1993), os baixos níveis de renda ainda configuram-se como um grande componente da pobreza, especialmente em países subdesenvolvidos, onde rendas baixas dão maior abertura a problemas severos como desnutrição, doenças negligenciadas, analfabetismo, discriminação salarial de sexo e raça e etc., construindo barreiras sociais que são verdadeiras armadilhas de privações, na medida em que impossibilitam a saída dos indivíduos pobres dessas condições de vulnerabilidade e impede-os de auferir maiores níveis de renda, inserindo-os em um círculo vicioso. Tal fenômeno, ao ser considerado chave do desenvolvimento dos países, dificulta cada vez mais a saída das nações da condição de subdesenvolvidas.

Ao serem enxergados como fenômenos multifacetados, a pobreza e o desenvolvimento passam a incorporar aspectos mais amplos e subjetivos. Gradualmente, os estudos mostram que as privações dos agentes vão além de fatores socioeconômicos. Um olhar mais apurado do indivíduo pobre mostra que ele anseia por sentimentos como dignidade, autoconfiança, esperança e até mesmo por voz política e outras sensações de pertencimento e participação em sociedade. A percepção subjetiva da pobreza e do desenvolvimento humano, levou os estudiosos do campo da economia comportamental a estudarem tais conceitos. Eles buscam entender, primordialmente, se a pobreza é capaz de afetar as tomadas de decisão econômica das pessoas através de influências em seu estado afetivo e, dessa forma, dificultar a saída dos indivíduos da condição de pobreza, afetando, sobretudo, as tomadas de decisão dos agentes em suas escolhas por políticas de desenvolvimento equivocadas. Tal abordagem configura-se, portanto, como uma extensão da análise da pobreza de Amartya Sen, na medida em que enxerga os obstáculos internos à mente dos indivíduos como uma restrição às suas capacidades e, portanto, afetam a liberdade dos agentes de levarem a vida que desejam em sociedade (MURAMATSU; ÁVILA, 2017).

Haushofer e Fehr (2014) ressaltam que estudos empíricos no campo do comportamento econômico realizado com pessoas em situações de pobreza indicam que viver nessas condições gera afeto negativo e estresse, efeitos que podem influenciar a tomada de decisão dos indivíduos. Os agentes que vivem em condição de pobreza tendem a ter baixa disposição para correr riscos e para realizar investimentos de longo prazo em áreas como educação e saúde, reduzindo as chances futuras de conquistar maiores níveis de renda. A pobreza, portanto, demonstra favorecer comportamentos que obstaculizam livrar-se dela. Os ambientes de privação em que os indivíduos vivem, são capazes de criar mecanismos que reforçam a situação de miséria na qual estão inseridos.

A ciência do comportamento econômico está cada vez mais comprometida a criar ferramentas analíticas que possibilitem melhor identificação dos desvios comportamentais existentes, objetivando a criação de políticas cada vez mais eficazes. Para tanto, esse ramo da ciência lança propostas de revolução das estruturas do desenvolvimento e abre portas para novos rumos ligados à psicologia os quais a economia pode seguir. A abordagem da economia comportamental levantou o debate sobre 
pequenas intervenções na arquitetura de escolha, os nudges, com a proposta de que são condutas socialmente desejáveis para elevar o bem-estar geral principalmente em escolhas de políticas públicas que visam o desenvolvimento. Nesse sentido, os economistas comportamentais acreditam que ao enxergarem o desenvolvimento como expansão das capacidades, as mudanças devem ocorrer em áreas desde as micro institucionais até em padrões comportamentais, que possam garantir o direito de as pessoas exercerem suas próprias vontades.

Apesar das duras críticas ainda existentes ao método empírico e experimental, o avanço do estudo da pobreza e do desenvolvimento humano pelo campo da economia comportamental possibilitou um novo olhar para esses ramos de estudo, capaz de encontrar resoluções mais concretas para tais fatores através da observação do comportamento dos indivíduos. Essa abordagem abre portas para a identificação de problemas e estruturação de políticas públicas através de perspectivas não negligenciáveis e sugere amplos estudos futuros que parecem ser promissores para um entendimento mais rico desses fenômenos, das suas formas de medição e, principalmente, de meios para sair das situações de vulnerabilidade e miséria e alcançar maiores níveis de desenvolvimento humano.

\section{REFERÊNCIAS}

ANAND, P.; LEA, S. The psychology and behavioural economics of poverty. Journal of Economic Psychology, v. 32, p. $284-293,2011$.

BANCO MUNDIAL. Relatório sobre o desenvolvimento mundial 2015: mente, sociedade e comportamento. Washington, DC: Banco Mundial, 2015. Disponível em: <http:/documents.banquemondiale.org/curated/ en/367881468328822092/Vis\%C3\%A3o-Geral-Mente-Sociedade-e-Comportamento>. Acesso em: 10 Ago. 2017

BANERJEE, A. V.; DUFLO, E. The economic lives of the poor. The journal of economic perspectives, v. 21, n. 1, p. 141-167, 2007.

Lisboa: Temas e Debates-Circulos Leitores, 2012.

BANERJEE, A.; MULLAINATHAN, S. The shape of temptation: Implications for the economic lives of the poor. National Bureau of Economic Research, 2010.

BERTRAND, M.; MULLAINATHAN, S.; SHAFIR, E. A behavioral-economics view of poverty. The American Economic Review, v. 94, n. 2, p. 419-423, 2004.

CARDOSO, A. L. Indicadores sociais e políticas públicas: algumas notas críticas. Proposta, v. 77, p. 42-53, 1998.

CODES, A. L. M. A trajetória do pensamento científico sobre pobreza: em direção a uma visão complexa.

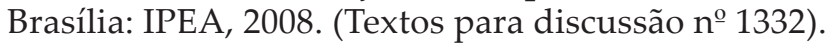

CRESPO, A. P. A.; GUROVITZ, E. A Pobreza como um Fenômeno Multidimensional. RAE - Eletrônica, v. 1, n.2, p. 1-12, 2002.

DATTA, S.; MULLAINATHAN, S. Behavioral design: a new approach to development policy. Review of Income and Wealth, v. 60, n. 1, p. 7-35, 2014.

DELANEY, L.; LADES, L. Present bias and everyday self control failures, 2015. University of Stirling. Disponível em: <http://www.stir.ac.uk/management/ research/economics/workingpapers/>. Acesso em: 15 Ago. 2017

GUIMARÃES, J. R. S.; JANNUZZI, P. de M. IDH, Indicadores Sintéticos e Suas Aplicações. Uma Análise Crítica. Revista Brasileira de Estudos Urbanos e Regionais, v. 7, n. 1. p. 73 - 90, maio. 2005.

HAUSHOFER, J.; FEHR, E. Sobre a psicologia da pobreza. In: ÁVILA, Flávia; BIANCHI, Ana Maria (Orgs). Guia de economia comportamental e experimental. São Paulo: Economia Comportamental.org, 2015.

JÄNTTI, M. et al. Poverty and welfare measurement on the basis of prospect theory. Review of Income and Wealth, v. 60, n. 1, p. 182-205, 2014. 
KAHNEMAN, D. Rápido e devagar: duas formas de pensar. Rio de Janeiro: Objetiva, 2012.

MANI, A. et al. Poverty impedes cognitive function. Science, v. 341, n. 6149, p. 976-980, 2013

MARTINI, R. A. et al. Um ensaio sobre os aspectos teóricos e metodológicos da economia da pobreza. Belo Horizonte: UFMG/Cedeplar, 2009.

MESTRUM, F. Mondialisation et pauvreté: de l'utilité de la pauvreté dans le nouvel ordre mondial. Paris:

L'Harmattan, 2002.

MULLUNATHAN, S.; SHAFIR, E. Escassez: uma nova forma de pensar a falta de recursos na vida das pessoas e nas organizações. Rio de Janeiro: Best Business, 2016.

MURAMATSU, R. Lições da economia comportamental do desenvolvimento e pobreza. In: ÁVILA, Flávia; BIANCHI, Ana Maria (Orgs). Guia de economia comportamental e experimental. São Paulo: Economia Comportamental.org, 2015.

MURAMATSU, R.; AVILA, F. The behavioral turn in development economics: a tentative account through the lens of economic methodology. Revista de Economia Política, v. 37, n. 2, p. 363-380, 2017.

PROGRAMA DAS NAÇÕES UNIDAS PARA O DESENVOLVIMENTO (PNUD). A Verdadeira riqueza das nações: vias para o desenvolvimento humano, 2010. Disponível em: <http://www.mpsp.mp.br/portal/page/ portal/cao_civel/acoes_afirmativas/PNUD-IDH-2010-Completo.pdf >. Acesso em: 10 Ago. 2017

ROMÃO, Maurício E.C. Considerações sobre o conceito de pobreza. Revista Brasileira de Economia, v. 36, n. 4, p. 355-370, out/dez. 1982.

ROMERO, J. A. R. Analise espacial da pobreza municipal no estado de Minas Gerais - 1991 - 2000. In:

ENCONTRO NACIONAL DE ESTUDOS POPULACIONAIS, 14., 2006, Caxambú. Anais... . Caxambú: ABEP, 2006. p. 1 - 19.

SALAMA, P.; DESTREMAU, B. O tamanho da pobreza: economia política da distribuição de renda. Petrópolis: Ed. Garamond, 2001.

SARAIVA, R. Economia comportamental do desenvolvimento. Boletim de Ciências Econômicas, v. 62. n. 3, 2014.

SEN, A. O desenvolvimento como expansão de capacidades. Lua Nova: revista de cultura e política, n. 28-29, p. 313-334, 1993.

Desigualdade reexaminada. Editora Record, Rio de Janeiro, 2001.

. Desenvolvimento como liberdade. Editora Schwarcz S.A, São Paulo, 2013.

SHAH, A. K.; MULLAINATHAN, S.; SHAFIR, E. Some consequences of having too little. Science, v. 338, n. 6107, p. 682-685, 2012.

SIMON, H. A. A Behavioral model of rational choice. Quartely Journal of Economics, v. 69, n. 1, p. 99-118, 1955.

SPEARS, D. Economic decision-making in poverty depletes behavioral control. The BE Journal of Economic Analysis \& Policy, v. 11, n. 1, 2011.

THALER, R.; SUNSTEIN, C. Nudge: improving decisions about health, wealth and happiness. New York: Penguin Books, 2009.

TOWNSEND, P. Poverty in the United Kingdom: a survey of household resources and standards of living. London: Allen Lane and Penguin Books, 1979 
Conceptualising poverty. Dynamics of Deprivation, Aldershot: Gower, p. 31-44, 1987.

Introduction, Compendium of best practices in poverty measurement. Expert Group on

Poverty Statistics (Rio Group), Rio de Janeiro, September, 2006.

VAZ, A. C. N.; SILVA, Y. C. Análise do IDH-M e possibilidades de aprimoramento para captação mais apurada dos efeitos das Políticas de Desenvolvimento Social. Secretaria de Avaliação e Gestão da Informação - SAGLI, Ministério do Desenvolvimento Social e Combate à Fome. Estudo técnico, n. 20, 2013.

VERMEERSCH, C. KREMER, M. School meals, educational achievement, and school competition: evidence from a randomized evaluation. World Bank Policy Research Working. n. 3523, 2004.

WILBER, G. Poverty: A new perspective. Lexington: The University Press of Kentucky, 1975. 